\title{
XXIII.
}

\section{Beiträge zur Pathologie und pathologischen Anatomie des centralen Nervensystems.}

Von Prof. Dr. Friedrich Schultze in Heidelberg.

(Hierzu Taf. X.)

VII.

Ueber Spalt-, Höhlen- and Gliombildung im Rückenmarke und in der Medulla oblongata.

Trotzdem in dem letzten Decennium eine Anzabl grösserer und wichtiger A rbeiten über die so auffallende Spalt- und Höhlenbildung der Medulla spinalis veröffentlicht wurde, so ist noch keineswegs eine Einigung in der Auffassung über die Entstehungsweise dieser abnormen Zustände erzielt.

Während, um nur die letzten Autoren zu nennen, welche sich mit dem vorliegenden Gegenstande bescbäftigt haben, Westphal und Simon die Höhlen aus dem Zerfalle von gewucherten Gliamassen hervorgehen lassen, sucht Leyden aus der Lage und Beschaffenheit der Höhlen im Vergleiche mit sehr früh sich entwickelnden Höhlenbildungen beim kindlichen Rückenmark die Theorie zu begründen, dass es sich hierbei um Abnormitäten in der Bildung des Centralkanales, also um eine congenital vorgebildete Störung handle.

Ganz neuerdings stellt endlich Langhans (d. Archiv Bd. 85) die Meinung auf, dass die Spaltbildung in manchen Fällen durch Stauung hervorgerufen werde, welche ihrerseits ihren Grund in abnorm gesteigertem Drucke innerhalb der Kleinhirngrube habe, dass es sich um eine Art von Oedemspalten handle.

Ohne vorerst in eine Discussion über die Berechtigung dieser verschiedenen Anschauungen einzutreten, will ich in möglichst kurzer Fassung neues Material zur Lösung der Frage beibringen. 
Tüchon's Archio. Bd. IXXXVII.

Taf: $\bar{X}$.
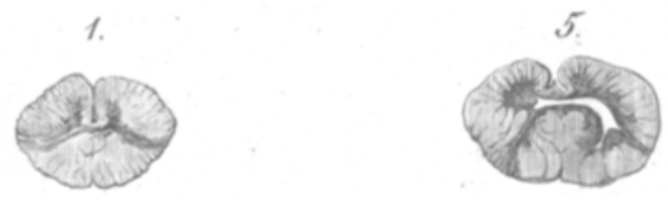

2.

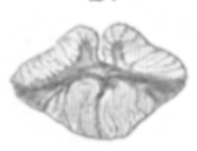

6.

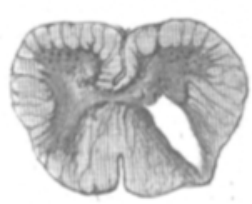

3.

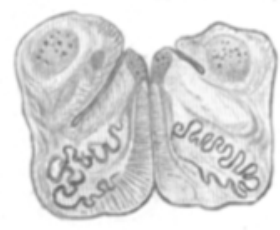

7.

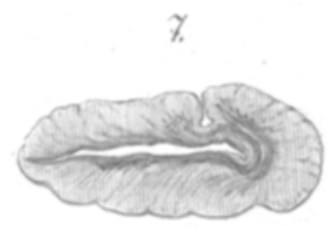

4.

8.
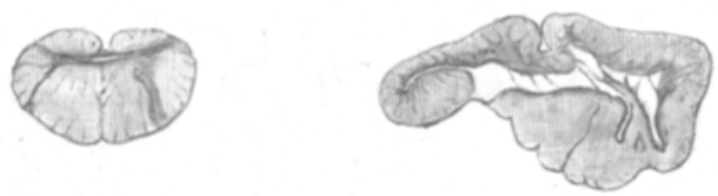

F. Teith del.

W. Grotmannise. 


\section{Beobachtung (').}

Contracturea der Unterextremitaten, chronische Gelenkaffection. - Eigenthümlicbe Spaltbildung In der Medulla oblongata; transversale Spalte $1 \mathrm{~m}$ Halstheile, Wucherang des Ependyms im Dorsaltheile des Rückenmarks; Degeneration der Seitenstränge.

J. K., 49jähriger Arbeiter. Im Jahre 1852 Schmerzen im rechten Bein, welche den Kranken 24 Wochen an's Bett fesselten; nachher blieb Steifigkeit in dem Beine zurück. Ende 1873 wochenlang Schmerzen in der Gegend des Austrittes der rechtsseitigen Sacralnerven, die besonders bei Bewegungen des Bückens sich einstellen und das Gehen hindern. Druck auf die linke Seite des 0 s sacrum ist schmerzhaft; Bewegungen der linken Unterextremität ebenfalls, besonders die Rotation des linken Oberschenkels im Hüftgelenk sehr empfindlich. Sensibilität normal. Die erwähnten Schmerzen nehmen im weiteren Verlaufe des Leidens zu; es tritt permanente Beugestellung beider 0berschenkel ein, so dass das Gehen völlig unmöglich wird. Es blieb fraglich, ob die vorhandenen geschilderten Symptome durch eine doppelseitige Arthritis und zwar besonders Coxitis zu Stande kamen oder ob eine spinale Läsion noch ausserdem oder gar allein vorhanden sei.

Der Kranke erlag im Jahre 1877 einer acuten Pneumonie, ohne dass sich an der permanenten Contractur etwas geändert hätte.

Die Section (Prof. Arnold) ergab Bronchitis und Pneumonie; ausserdem Arthritis deformans besonders der Hüftgelenke. -

Bei der Eröffnung der Rückenmarkshöhle fand ich Folgendes: Die Hăute normal, Medull. spinalls von sehr geringem Volumen, Halstheil auffallend platt, mit einem Querspalt versehen.

Nach der Erbärtung ergaben die Maasse für die Lendenanschwellung ín maximo $8 \frac{1}{2} \mathrm{Mm}$. in frontalem, $7 \mathrm{Mm}$. in sagittalem Durchmesser; im Halstheile $11 \mathrm{Mm}$. in frontaler, und nur $6 \mathrm{Mm}$. in sagittaler Richtung.

Im Allgemeinen zeigen sich ferner 2 wei Arten von Abnormitäten:

1) Im Dorsal- und Halstheile eine Verfärbung und Degeneration der hintersten Abschnitte der Seitenstrănge. Der Bezirk dieser Degeneration nimmt auf dem Querschnitte eine dreieckige Form ein; der eine Schenkel des Dreiecks grenzt an die Rückenmarksperipherle, der zweite liegt den Hinterhörnern dicht an. Es werden von der Degeneration Theile sowobl der Pyramiden- als der Kleinhirnseitenstrangbahnen betroffen. Das Volumen der Seitenstränge ist in Folge der geschilderten Veranderung verringert und geschrumpft; der Contour derselben ist im grössten Theile der dorsalen Partien anstatt nach aussen convex nach innen eingebogen und die Hinterhörner verlaufen fast völlig gestreckt in der Richtung der Frontalebene (Fig. 2).

2) Sogenannte periependymäre Sclerose des grössten Theiles des Dorsaltheiles und Spalt. und Höblenbildung in den Hinterhörnern desselben. In

1) Die klinischen Notizen in den einzelnen Fällen verdanke lch der Güte der Herren Friedrelch, Czerny, v. Dusch und Erb; den grössten Theil der betreffenden Kranken babe ich selbst gelegentlich untersucht: 
der Halsanschwellung and im obersten Halstbeile bis nahe an die Pyramidenkreuzung geht der Spalt sogar quer durch die Medulla hindurch, die gesammten Hinterstränge nod den hinteren Theil der Hinterbörnervon den vorderen Partien vollständig abtrennend. -

Im Einzelnen zeigt sich die Lendenanschwellung in ibrer unteren Hälfte normal; der Centralkanal ist auf dem Querschnitte fast kreisrund and völlig durch grosse Rundzellen obliterirt, wie sehr häufig bei Erwachsenen. In seiner Umgebung keine ungewöhnliche Anhäufung von Zellen. - In der Gegend der $\mathrm{Py}$ bahnen zeigt sich eine leichte Sclerose.

In der oberen Hälfte der Lendenanschwellang befinden sich, nach aufwärts za an Zahl immer mehr zunehmend, grössere Mengen von Gliazellen zu beiden Seiten des obliterirten Centralkanals von gleicher Beschaffenheit wie die obliterirenden Zellen. Sie lassen sich bis an die Basis der Hinterhörner hinein verfolgen. Einzelne Gefässe der Hinterhörner, und zwar Capillaren, haben eine stark verdickte, kernarme Wand, sind also, wie man sich ausdrückt, sclerotisch.

Im Uebergangsthell der Lendenanschwellung zum Dorsaltheil nimmt die Wacherung der Gliazellen die ganze hintere Commissur ein, welche mit ihnen wie vollgepflastert ist, und erstreckt sich bis in die Substanz der Clarke'schen Säulen selbst hinein. Die Zellen zeigen sich dabei theilweise in gleicher Weise in Form von Nestern angehäuft, wie oft unter normalen Verbältnissen in unmittelbarer Nähe des Centralkanals.

Ausserdem ist in der Mitte des linken Hinterhorns, durch die ganze Ausdehnung desselben hindurch bis nahe an die Peripherie sich hinziehend, schon makroskopisch ein ganz feiner Spalt an dem völlig unverletzten und gut gehärteten Präparat slchtbar, welcher bei der Anfertigung von Schnitten noch deutlicher klafft, auch wohl noch etwas einreisst, und der in seiner nächsten Umgebung elne grosse Menge von längs- und querdurchschnittenen pathologischen Gefässen mit sehr verdickter Wand und ausserdem vermehrte Gliafasern zeigt.

In Flg. 1 ist diese Spaltbildung angedeutet; die Seitenstränge zeigen In ihrer äussersten Spitze in der Gegend des Winkels zwischen Hinterhörnern and Rückenmarksperipherie elne dunkle Schattirung, der hler stärker werdenden Sclerose entsprechend.

Im unteren und mittleren Dorsaltheile zeigt slch (Fig. 2) die Wucherung der centralen Ependymzellen viel stärker; sie hat ausser der hinteren auch fast die ganze vordere Commissur bis an den Boden der vorderen Längsspalte vernichtet, und infiltrirt nach hinten zu noch das mediane Septum der hinteren Längsspalte and die angrenzenden Hauptbindegewebşzüge der Hinterstränge.

Von dieser centralen gliomatösen Partie aus, welche nebenbei bemerkt wie in anderen sonst beschriebenen Fällen auf dem Querschnitt eine elliptische Begrenzungslinie zeigt, erstreckt sich nun mitten in die Hinterhörner hinein und in deren Richtung, mehr nach den Seitensträngen als nach den Hintersträngen zu gelegen, eln schmaler Streifen, der nur aus gewuchertem Gliagewebe besteht: Er zieht sich bis an die Pybahnen der Seitenstränge heran, wo er dann unmittelbar in die schon erwähnte Sclerose dieser Partie übergeht. Auch hier sieht man inmitten dieser stärkeren Anhäufung von Gliazellen und Gliafasern in den Hinter- 
hörnern eine grosse Menge von sclerotischen Gefässen und an verschiedenen Stellen eine sehr dentlich sichtbare Lockerung des Gefüges der Glia. Der vorher geschilderte Spalt in dem linken Hinterhorn, welcher gewissermaassen die maximale Ausbildung dieser Lockerung darstellt, ist wleder verschwunden.

In dem Centrum der erwähnten elliṕtisch begrenzten Gliawucherung, welche der Gegend des Centralkanales entspricht, sind die Gliafasern und Kerne viel spärlicher; das Präparat wird dadurch schon makroskopisch an diesen Stellen viel heller gefärbt und durchsichtiger. An einer Stelle kann man auf Serienschnitten deutlich den Uebergang dieser centralen Partien von rareficirtem Gewebe in eine makroskopische wahrnehmbare Höhle direct verfolgen, welche also keineswegs den ursprüglichen Centralkanal darstellt, sondern eine durch den Schwund von Gliazellen entstandene, zuerst kleinere, dann umfangreicher werdende, secundäre, spaltförmige Oeffnung. Weiter nach oben zu schliesst sich die Höhle bald wieder und findet sich somit nur in einer geringen Höhenausdehnung des Dorsaltheiles, während eine centrale Rarefication der gewucherten Glia in dem ganzen genannten Abschnitte des Rückenmarkes sich zeigt.

An einer anderen Stelle im Dorsaltheile zeigt sich inmitten des feinfaserigen und engmaschigen Gefüges der Gliazellen eine grössere Menge feingestreifter, schwach gefärbter, wellig gebogener und papillenartig gewundener Bindegewebszîge, welche nur sehr wenig Kerne führen und somit von glelcher Beschaffenhelt sind, wie hăufig die Grenzmembranen von Rückenmarksspalten, so wie sie ganz ähnlich auch Strümpell in einem Falle von Hydromyelus beschreibt, welcher mit dem unsrigen überhaupt eine grosse Aebnlichkeit hat (Arch. f. Psychiatr. Bd. X. Heft 3. „Beiträge zur Pathologie des Rückenmarks"). In kleinen Hohlräumen, welche innerhalb dieser Bindegewebszüge und ebenso nach dem benachbarten Gliagewebe zu sich befinden, zeigen sich hyaline kernlose Massen von völlig homogenem Gefüge, wie sle auch Langhans schildert und wie sie sich auch sonst besonders um grössere Gefässe herum, als sogenannte byaline Schollen nicht selten finden. Würden derartige Hohlräume durch stärkere Erweiterung zu völliger Spaltbildung führen, so müsste die entstehende Höhle oder wenigstens ein Theil derselben schon von vornherein von dem genannten Bindegewebe als Grenzmembran eingefasst sein. Direct konnte ich in diesem Falle eine derartige Entstehungsweise von grösseren Höhlen nicht nachweisen.

Im obersten Dorsaltheile wird die Gliawucherung Im Ependym an Masse und an Zellenreichthum allmählich immer geringer; es zeigt sich hier eine grössere Höhle im linken Hinterhorn, welche an der Spitze des Hinterhorns bis zur Pia reicht und dort nur von dieser begrenzt wird. Sie ist ausgekleidet von einer dünnen, sehr zellenarmen, wellig fibrillären Bindegewebsmembran von der gleichen Beschaffenbeit wie die vorher geschilderten fibrillären Massen inmitten der gewucherten Glia.

Ein Centralkanal ist im ganzen Dorsaltheile nirgends vorhanden; er ist vollständig in der gliösen Neubildungsmasse aufgegangen.

Im Halstheile blelbt die Gliawucherung weniger stark; dafür zeigt sich in demselben und umgeben von Gliafasern ein breiter $Q$ uerspalt, welcher durch die ganze hintere Commissur hindurchgeht, dann beiderseits in die Substanz der 
Hinterhörner elndringt und bis an die Spitze derselben entweder bis an die Pia selbst oder his nahe an die Pia slch hlnzieht. Der hintere Theil der Hinterhörner wird dadurch nebst den Hintersträngen völlig von den Seitensträngen und der vorderen grauen Substanz in der Höhe von mehreren Zollen völlig abgetrennt. Die Wände dieses Spaltes, welcher sich nirgends zu einer grösseren Höhle erweitert, sondern in seinen vorderen und hinteren Abschnitten sich beinab berührt, werden theilweise von Bindegewebsmembranen, theilweise von gewöhnlichen Gliafasern gebildet. Schmale Balken und Brücken von Gliagewebe verbinden an einzelnen Stellen die gegenüberliegenden Spaltwandungen. -

Sowohl in der vorderen Wand desselben, und zwar seitlich verschoben, als auch in der hinteren Wand gerade in der Mitte, dem Grunde der vorderen Längsspalte gegenüber, liegt eine Anzahl von Epithelzellen, den Rest des Centralkanales darstellend. $\mathrm{Ob}$ derselbe früher obliterirt oder offen war, lässt sich natürlich nicht eruiren. In der Umgebung der Wandungen des Spaltes zeigen sich abnorme Mengen von Gliafasern mit wenig Kernen, ausserdem eine grosse Menge sclerotischer Gefässe.

Die Gestalt der Vorderhörner und der Hinterbörner, letztere bis auf den durch den Spalt verursachten Defect, unverändert; keinerlei Verdrängungserscheinungen. Bei dem Anfertigen von Präparaten klaftt natürlich der Spalt und nimmt die Form einer weiten Höhle an, deren Wandungen von einander beträchtlich absteben. Im frischen, wie im gehärteten Zustande des Rückenmarkes war das, wie gesagt, nichı der Fall.

In der Medulla oblongata endlich nimmt die geschilderte Spaltbildung eine andere Form an.

In der Gegend etwa der Mitte der Höhe der Hypoglossuskerne zeigt sich das in Fig. 3 gezeichnete Bild. Lateralwärts von beiden Hypoglossuskernen zieht sich in schräger Richtung von hinten und innen nach vorn und aussen links ein tieferer, rechts ein flacherer Spalt hinein, um den herum sich abnorme Anhäufungen von Gliafasern und Kernen zeigen. Dlese Gliafasern sind von sehr lockerem Gefüge und keineswegs besonders massenhaft; nur in der Nähe der Einmündung der Spalte in den 4. Ventrikel zeigt sich eine starke Anhänfung von Gliazellen. Die Grenze der Spalten bilden zum grossen Theil sclerotische Gefässe, welche dieselbe Richtung wie jene einhalten.

Die Pyramiden sind etwas abgeflacht, weniger voluminös, aber obne deutllche Degeneration.

Diese beiden beschriebenen Spalten lassen sich bis in die Pyramidenkrenzung hinein nach unten weiter verfolgen; sie gehen dabei immer von der Gegend des Centralkanals und seines Ependyms aus; nur im untersten Abschnitt der Decussationsstelle sieht man nur noch die lateralen Partien derselben allein übrig bleiben, welche durch grössere Mengen gesunden Gewebes von der Mittellinie getrennt sind, andererseits aber bis an die Peripherie, also an die Pia sich erstrecken. Ausserdem liegen sie stets in den hinteren Abschnitten des verlängerten Markes, am hinteren Rande der gelatinösen Substanz in der Richtung von binten innen nach vorn und aussen dahinziehend.

Mit dem Verschwinden der Pyramidenkreuznng tritt dann nach unten zu der 
geschilderte complete Querspalt ein, dessen mittlere Partie also durch das Eintreten der Decussation zam Verschwinden gebracht wurde, so dass nur die peripherischen Abschnitte der Spalten in den Hinterhörnern und in der Nähe derselben bestehen blieben. -

In der Höhe des oberen Endes der Hypoglossuskerne hört die Spaltbildung nach oben hin auf. -

Die Rückenmarkssubstanz selbst ist ausser der Degeneration in den Seitensträngen intact; myelitische Heerde, Aufquellungen von Axencylindern llessen sich $\mathrm{nicht}$ finden; ebenso feblte eine deutliche ödematöse Durchtränkung, wie man sie z. B. bei acuter Meningitis sieht. Die Meningen und Wurzeln zeigen nichts Besonderes.

\section{Beobachtung II.}

Neurose der Oberextremitäten, während eines Typhus entstanden. Später Parästhesien in allen Extremitäten und Schmerzen vorzugsweise im Kreaz. Hysterie? - Gliomatose und Spaltbildung im Ependym und la den Hintersträngen.

Ag. H., Näherin, war bis auf chlorotisebe Beschwerden früher gesund gewesen and wurde in der Heidelberger med. Klinik im Sommer 1872 an Typlas behandelt, welcher etwa 4 Wochen dauerte. Während der 3. Fieberwoche trat eine auffällige Schwäche der linken Oberextremităt ein, welche wăbrend der Reconvalescenz noch fortbestand, später aber wieder schwand. Dafür stellte sich aber ein Gefühl von Pelzigsein in beiden Armen und Händen ein, das bestehen blieb und auch einer längeren galvanischen Behandlung trotzte. Zeitweise steigerte es sich bis zum Taubbeitsgefühl. Ausserdem fand sich immer mehr zunehmendes Kreuzweh ein, fernerhin starke Schmerzen in Armen und Beinen, so dass die Kranke sich in ihren letzten Lebensjahren nur mit Anstrengung fortbewegen konnte. Atrophien der Muskeln und Paralysen bestanden niemals. Die fortdauernden Klagen der Patientin über ihre Kreuzschmerzen wurden mit den vorhandenen Lageveränderungen des Uterus in Verbindung gebracht; die sonstigen geschilderten Beschwerden wurden von mir zum Theile als hysterische aufgefasst.

Wegen eines eingeklemmten Leistenbruchs musste 1881 operirt werden; die Kranke starb an den Folgen dieser 0peration, 46 Jahre alt, am 6. October 1881.

Da die Möglichkeit vorlag, dass während der typhösen Erkrankung ein abnormer Prozess In der Med. spinal. sich entwickelt baben konnte, welcher zu jener damaligen Affection der Oberextremitäten Anlass gegeben hatte, wurde von mir der Rückenmarkskanal geöffnet, und ich fand eine Syringomyelie.

Die anatomischen Verhältnisse verhielten sich analog wie in elner grösseren Anzahl schon sonst veröffentlichter Fälle; ich kann mich daher in der Bescbreibung kurz fassen.

Die ganze Lendenanschwellung normal; Centralkanal obliterirt. Im untersten Dorsaltheil beginnt, sehr rasch an Ausdehnung zunehmend, eine Gliavermehrung in der vorderen Hälfte beider Hinterstränge; bald zeigt sich die genannte Partie völiig von Gliazellen durchsetzt, die niemals dicht gedrängt neben einander sich finden, sondern stets von zahlreichen sehr eng mit einander verflochtenen Gliafasern getrennt sind. Die Nervenfasern sind völlig 
geschwanden. Die neugebildete Masse hat eine röthlich-braune Farbe, welche von reichlichem Blutpigment berrührt.

Auch die Clarke'schen Sãulen werden weiter aufwärts durch Gliagewebe ersetzt, welches sich hauptsăchlich durch den grossen Zellenreichthum von der gewöhnlichen Sclerose unterscheldet.

Etwas weiter nach oben tritt etwa im Centrum der neugebildeten Massen schon makroskopisch sichtbar eine graullche Verfärbung mit Erweichnng der betreffenden Substanz auf, welche ein mehr schleimiges, gelatinöses Aussehen gewinnt. Beim Anfertigen von Querschnitten erhält man Substanzverluste an dieser Stelle. Weiter oben ist auch makroskopisch eine kleine centrale Höhle wahrnehmbar.

Der CentralkanaI hat mit dieser Höble gar nichts zu thun, er liegt obliterirt vor den gliösen Massen.

So liegen die Verbältnisse fast im ganzen Dorsaltheile: Die neugebildete Substanz nimmt immer den angegebenen Platz in den vorderen Partien der Hinterstränge und in der hinteren Commissur ein, bald mehr, bald weniger welt auf die Clarke'schen Säulen und auf die laterale Grenze der mittleren Partien der grauen Substanz übergreifend; in der Mitte derselben zeigt sich entweder nur elne sehr erhebliche Rarefication der Gliazellen und Gliafasern, die stark von den oft nesterförmig angeordneten reichlichen Zellenwucherungen der peripherischen Abschnitte absticht, oder eine völlige Einschmelzung mit Höhlenbildung, deren Uebergang in die atrophischen Partien man direct verfolgen kann. Der Centralkanal hat mit diesen Veränderungen nichts zu thon. An manchen Stellen helfen seine Zellen die vordere Grenze der gliomatösen Neubildung bilden, an anderen liegt seine Zellenmasse unversehrt vor derselben, an wieder anderen ist er völlig ununterscheidbar in der sonstigen Zellenmasse untergegangen.

Körnchenzellen lassen sich am erhärteten Präparate in den atrophirten Theilen der Neubidung nicht finden; in der Umgebung der Neubildung ziemlich viele Corpora amylacea; die angrenzenden Gliazüge unregelmässig verbreitert und atrophirte Nervenfasern führend.

Im oberen Dorsaltbeil und unteren Halstheil liegt die gliomatöse Masse mehr nach dem linken Hinterhorn zu, diesen zum Theil ersetzend; weiter nach oben wird (in etwa $1 \mathrm{Cm}$. Höhe) fast der ganze linke Hinterstrang und die Substanz des linken Hinterhorns ergriffen.

Auch hier wieder eine centrale Erweichung und Höhlenbildang (welche hier weit von der Gegend des Centralkanals entfernt liegt und nirgends mit ihm zasammenhängt). Die Höhle klein; sie tritt wie überhaupt im ganzen Dorsaltheile an Ausdehnung sehr gegen die soliden Massen der Gliawucherung zurück.

ln der Mitte des Halsthelles wird wieder der vordere Abschnitt beider Hinterstränge der Sitz des pathologischen Prozesses; die Höhle im Centrum wird grösser; der Centralkanal liegt hier in geringer Höhenausdehnung etwas erweitert und mit Gylinderepithel bekleidet vor der Gliamasse, nirgends in seiner ganzen Höhe mit der genannten Höhle communicirend. Die Erweiterung des Centralkanals ist nur eine geringe.

Weiter nach oben zu nimmt die Ausdehnung der Gliawucherung noch za, 
nimmt fast die ganzen Hinterstrănge ein;, in welchen sich zwei kleinere Höhlen finden, deren eine ganz periphertsch nahe der Pia in den Goll'schen Strängen liegt, während die andere sich theils im Hinterhorn, theils in den mittleren Abschnitten der Funic. cuneati placirt. -

Beide Hinterhörner erscheinen durch die Gliamassen etwas nach aussen gedrängt; ausserdem Ist der linke Hinterstrang etwas eingeschrumpft. Im Dorsaltheile sind keine deutlichen Verdrängungserscheinungen sichtbar. -

Die Gefässe sind inmitten der Neubildung ziemlich spärlich, haben aber fast alle stark verdickte Wandungen; ebenso sind die Gefässe in der Nähe der Neubildung sclerotisch.

Die Meringen zeigen nichts Abnormes; die Rückenmarkssubstanz in der Nähe der Neubildung normal; die Medulla oblongata fehlt leider. -

\section{Beobachtung III.}

Imbecillität; peripherische Lăhmang. - Hydrocephalus; Spalt bildang im Rückenmark; partielle Atrophie der Vorderstränge und Vorderhörner im Dorsaltheile. Degeneration der Goll'schen Stränge im Halstheile. - Abnormitäten im Rückenmarksbau sehr eigenthümlicher Art. -

P. B., 53 Jahre alt. - Der Kranke ist klein und schwächlich gebaut, von geringer Intelligenz. Er hat seit selnem 24. Lebenjahre einen Kropf, der im letzten Jabre raseh zu wachsen anfing und in seiner Umgebung Drüsenanschwellnngen zeigte. Die Exstirpation der carcinomatösen Struma erfolgte am 18. März 1881 anf der hiesigen chirurgischen Klinik. Die Wunde beilte fieberlos. Am 30. April 1881 Radialislähmung der linken Hand; die von mir vorgenommene Untersuchung ergab Paralyse der linken Hand- und Fingerextensoren und die Mittelform der Entartungsreaction in denselben. Triceps, Supinat. long. sind intact. Die Lähmung ergriff in den nächsten Tagen auch andere Armnerven, so dass am 8. April vollständige motorische Paralyse im linken Radialis-, Medianus- und Ulnarisgebiet bestand, soweit die von den genannten Nerven versorgten Muskeln für die Finger und die Hand in Betracht kamen. Im Ulnarisgebiet ausserdem beträchtliche Herabsetzung der Sensibilität; die electrische Untersuchung ergab Im IInaris und und Medianus nebst den dazugehörigen Muskeln keine Veränderung. Die Mittelform der Entartungsreaction im Radialisgebiet besteht noch.

Am 12. April stärkere allgemeine Schwäche, auch im rechten Medianusgebiet leichte Parese. - Electrische Erregbarkeit hier normal.

An der linken Hand und am linken Vorderarm besteht jetzt in allen Muskeln mit Ausnahme des Supinator longus volle Entartungsreaction. Die Lähmung wurde für eine peripherische angesehen. Die Kräfte des Kranken verfallen rasch; am 15. April 1881 erliegt er einer Bronchitis und Pnenmonie.

Die Section ergab acute Pnenmonie mit partieller Lungengangran. Entsprechend dem 7. Halswirbel findet sich hauptsächlich links, aber auch rechts eine markige Geschwulstmasse, welche um die Gefässe und die Züge der Nervenplexus herum verlänft und längs der letzteren in kleinem Umfange in den Wirbelkanal durch die Intervertebrallöcher hineingewuchert ist. - 
Im Wirbelkanal selbst fand ich zwischen Wirbeln und Dura besonders auf der linken Seite ejne grössere Menge weicher, graulich verfärbter Substanz, die in die Intervertebrallöcher hineingeht.

Das R ückenmark selbst ist sehr weich, ziemlich dünn, mit klaffendem, verbreiterten, queren Centralspalt (Centralkanal?) im Halstheil und grauer Verfärbung der Goll'schen Stränge im Hals- und Dorsaltheil. Die Vorderstrănge im Dorsaltheil ziemlich weich, ohne deutliche Contouren. - Häute und Wurzeln normal.

Gehirn von mittlerer Grösse; Seltenventrikel sebr erheblich erweitert, besonders die hinteren Hörner derselben, so dass die angrenzende Hirnsubstanz von abnorm geringer Dicke ist. Ependym hier und da leicht gekörnt, mejst ganz glatt, ziemlich derb.

Muskeln und Nerven des linken Arms lassen nichts Abnormes erkennen. Nur die Nerven sind etwas gelblich verfärbt; die Muskeln der Hand roth gefärbt, scheinbar völlig normal.

Die genauere Untersuchung des gehärteten Rückenmarkes ergiebt folgende eigenthümliche Resultate:

Die Lendenanschwellung etwas kleiner als normal; mikroskopisch ohne Veränderung. Der Centralkanal obliterírt. Im Uebergangsabschnitt zum Dorsaltheile tritt stärkere Zellenwucherung um den obliterirten Centralkanal auf, welche nach oben $z 0$ an Ausdehnung zunimmt und auch in das mediane Bindegewebsseptum der Hinterstränge sich fortsetzt.

Der Centralkanal ist im oberen Theile des genannten Abschnittes geöff net, von normaler Grösse und mit Cylinderepithel ausgekleidet. In sehr geringer Höhenausdehnung zeigt er sich verdoppelt; und zwar der eine zur Hälfte seines Lumens obliterirt, der andere mit byalinen Massen ausgefültt, welche vereinzelte grosse Rundzellen enthalten. Beide Centralkanäle sind von normaler Grösse, nirgends erweitert.

Weiter nach oben zu, im ganzen Dorsaltheile, wird die centrale Gliawucherung stärker; sie nimmt nicht nur die vordere Commissur, sondern auch einen Theil der Vorderhörner und selbst der Vorderstränge ein, wenn auch Keineswegs in der ganzen Höhe des Dorsaltheiles.

Dabei sind zugleich eigenthümliche Anomalien in dem Aufbau besonders der grauen Substanz vorhanden, welche sich leider nicht auf allen Querschnitten völlig genan analysiren lassen, da das Rückenmark in seinen vordersten Abschnitten sehr weich ist and nicht überall intacte Präparate liefert.

Die Vorderhörner sind im ganzen mittleren Dorsaltheil abnorm kurz; ihre vorderen Contouren stellen die geradlinige Fortsetzung der vorderen Begrenzungslinie der grauen Commissur dar; ihre Ganglienzellen liegen in den seitlichen Abschnitten der an Volumen nicht verringerten grauen Substanz ${ }^{1}$ ). Dabel sind die Vorderstrānge abnorm klein, so dass die Commissuren viel näher nach vorn zu liegen kommen als normal. Ferner ist das linke Hinterhorn in allen

1) Etwas ganz Analoges fand ich in einem Falle von Dementia paralytica (Westphal's Archiv Bd. XI „über die electrische Erregbarkeit bei der Dementia paralytica von Fischer and Schultze"). 
Abschnitten viel stärker und kräftiger entwickelt als das rechte, welches etwas schmächtiger als normal erscheint. Das sonderbarste ist dabei in einer geringen Höhenausdehnnng das Verhalten des Centralkanals (Fig. 4). Er ist abnorm breit, erstreckt sich durch dle ganze Breite der Commissur und ist zum grössten Theil mit Epithelzellen bekleidet. Dann erstreckt er sich aber noch an der vorderen Grenze des abgeflachten linken Vorderhorns, also vor demselben liegend, bis an eine Linie, welche man sich in sagittaler Richtung durch die Mitte der grauen Substanz hindurch gezogen denken kann und ist auch in diesem seinem Verlaufe zum guten Theile mit Epithel ausgekleidet. Schliesslich stösst er an einen Bindegewebszug, der sich in ziemlicher Breite bis zur Peripherie des Rückenmarkes an der Berübrungsstelle der Vorder- und der Seitenstränge fortsetzt. -

Auffallend verbält sich auch nach anderer Richtung der Epithelbelag des Kanals. Anstatt dass er wie gewöhnlich den Centralkanal auskleidet, liegt an einer circumscripten Partie in der Gegend der hinteren Commissur zwischen ihm und dem Lumen des Kanals eine mehr oder weniger dicke Schicht von Glia- und Ependymgewebe. -

Im unteren Dorsaltheil ist vor den Hintersträngen eine unregelmässige Spaltbildung vorbanden, die sich mit Sicherheit weder als erweiterter Centralkanal noch als durch Zerfall der gewucberten Glia entstandene Höhlung deuten lässt. -

In anderen Höbenabschnitten des Dorsalmarks ist der Centralkanal wieder obliterirt, in wieder anderen geschwunden und durch eine klaffende kleine Höhle ohne Eplthelbekleidang ersetzt.

Die centrale Gliawucherung in den beiden Commissuren, welche überall in geringen Dimensionen bleibt und keine Verdrängungerscheinungen erzeugt, geht direct in eine strichförmige Degeneration fibrillären Charakters über, welche sich links und rechts neben der hinteren Fissur von wechselnder Ausdehnung in der Richtung von binten nach vorn vorfindet.

Die Blutgefässwandungen in den abnormen Commissuren, Vorderhörnern, degenerirten Abschnitten stark verdickt. Die Rückenmarkssubstanz im Uebrigen normal. Die vorderen Wurzeln erscheinen trotz der Abnormităt der Vorderhörner nicht deutlich atrophisch und enthalten viele nicht nachweisbar veränderte Nervenfasern von normalem Volumen.

Der untere Halstheil (Fig. 5) bietet wieder eine Reihe anderweitiger Anomalien dar. Vor allem zeigt sich ein breiter $Q$ uerspalt, der sich durch die ganze hintere Commissur erstreckt und dann in das rechte Hinterhorn umbiegt. Der quergestellte Theil desselben ist vorzugsweise an seiner hinteren Grenze in weiter Ausdehnung mit Cylinderepithel bedeckt; der Centralkanal ist also abnorm breit.

Der im Hinterhorn gelegene Abschnitt ist dagegen mit einer zarten, dünnen, wellig gebogenen, fast kernlosen Membran ausgekleidet; in seiner Umgebung ist die unregelmässig gestaltete Hinterhornsubstanz mit zahlreichen Gliazellen durchsetzt. Ausserdem sind in dem rechten Hinterstrange neben den Nervenfasern von gewöhnichem Caliber rundliche kleinere Bündel von sehr dünnen Nervenfasern enthalten, die deutlich von den sonstigen Fasern abstechen und sonderbarerweise 
an ihrer Peripherie jedesmal ein grösseres Blutgefäss zu llegen haben, so dass sie etwa wie kleine Nervenwurzelbündel anssehen, welche die Hinterstränge der Länge nach durchsetzen. Eine andere Onregelmässigkeit ist die, dass die hintere Längsfissur nur halb so lang als normal erscheint, und dass auf der linken Seite neben dem abnorm weiten Centralkanal noch ein zweiter kleiner, normal grosser und balbobliterirter Nebenkanal sich findet.

Im mittleren Hals theile sind die Goll'schen Stränge völlig degenerirt; der Centralkanal ist nicht mehr so breit; an Stelle des Spaltes im unteren Halsthell zieht ron seiner rechten Ecke aus ein Ianger Strelfen von Bindegewebe mit wenig Kernen durch die Mitte des ganzen Hinterhorns bis fast an die Peripherie. Es stellt dieses Bindegewebe die stork verdickte Adventitia von Gefässen dar, welche in dem centralen Theile des Streifens zum Theil in der Längsaxe des Rückenmarks, sonst in der Richtung des Hinterhorns verlaufen. An der anderen Ecke des Centralkanals findet sich dieselbe Art von Gewebe, das aber hler theilweise spaltförmig auseinanderweicht und in seiner Umgebnng grössere Plaques jener eigenthümlichen hyalinen Substanz zeigt, welche man besonders oft in der Nähe von Blatgefässen antrifft, und die an anderen Stellen desselben Prăparats rothe und weisse Blutkörperchen in ihrer Mitte führt. - Ein doppelter Centralkanal ist nicht mehr vorhanden.

Im obersten Halstheile ist der Centralkanal nur noch ein wenig grösser als normal, irregulär geformt. Sonst ist alles bis auf die Degeneration der Goll'schen Stränge normal. Die grossen Gefässe in der hinteren Fissur haben eine stark verdickte Wand von dem gleichen Aussehn wie die vorher geschilderten Hinterhorngefässe, und führen in derselben vereinzelte Hämatosínkörner.

Die Medulla oblongata ist normal.

Die grossen Nervenstämme des linken Plex. brachlal. sind zum Theile von carcinomatösen Massen umgeben; die Lähmung der linken Armnerven ist somit peripherischen, nicht centralen Ursprungs. Ueber die Veränderang an den Muskeln der Hand und des Armes, welche trotz ihres scheinbar normalen Aussehens mehr oder weniger degenerirt sind, soll an dieser Stelle nicht ausführlicher berichtet werden.

\section{Beobachtung IV.}

Atrophie und Parese der oberen Extremitäten. Ausgedehnte Analgesie und partielle Anästhesie. Voräbergehend Bulbärerschei nungen. - Ausgedehnte Höhlenbildung im Rückenmark; besonders im Halstheile fast völlige Zerstörung der gesammten grauen Substanz; Spaltbildang in der Med. obl.; partielle Atrophie einer olive.

W. H., 37 Jahre alt, war früher im Wesentlichen gesund. Vier Jahre vor ihrem Tode Formicationsgefühl in belden oberen Extremitäten und zwar zuerst rechts. Vor drei Jahren fibrilläre Zuckungen in den Muskeln des rechten Arms und eigenthümliche Blasenbildungen an der rechten Hand. Es entstanden zeitweise ziemlich ausgedehnte Abhebungen der Epidermis, deren Inhalt allmählich eitrig warde und welche mit Hinterlassung einer schwieligen Hautverdickung heilten. 
Ein Jabr später gesellten sich heftige reissende Schmerzen in beiden Oberextremitäten dazu und bald darauf Seasibilitätsverlust der rechten Hand.

Ein Ende Mai 1880 in der Poliklinil des Herrn Hofrathes v. Dusch aufgenommener Status praesens ergab im Wesentlichen Folgendes: Erhebliche Abmagerung beider Oberextremitäten, besonders der kleinen Handmuskeln links; an beiden Händen Krallenstellung der Finger. Motorische Kraft der oberen Extremitäten stark berabgesetzt, etwas auch an den Beinen. - Pat. kann aber gut gehen und stehen und auch weitere Gänge ohne Ermüdung machen. - Die electrische Erregbarkeit in den Vorderarmen und Händen für die Muskeln stark herabgesetzt. Die Patellarreflexe erhalten, links viel schwächer als rechts.

Sensibllität an den Armen erloschen, an den Beinen normal; auch am oberen Theile des Rumpfes fehlt sie.

Keine Ataxie; kein Romberg'sches Symptom.

Pupillen normal; Augenbewegungen und Facialis ebenso. Sprache unbeholfen und langsam. -

Der Zustand der Kranken verschlimmerte sich langsam mehr und mehr; elne Zeit lang besteht Parese der Zunge, welche aber wieder verschwindet. D le Zunge ist ganz anastbetisch, so dass man obne Wissen der Kranken dieselbe mit Nadeln völlig durchstechen kann.

Im Sommer 1881 sind die Pupillen verengt; die rechte reagirt gar nicht, die linke wenig auf Licht. Die Sprache ist langsam und näselnd. Die Gegend der Sternalinsertion der 2. und 3. Rippe ist bei Berührung stark empfindlich, ebenso des 5.-7. Brustwirbels. Sonst ist die Pat. am ganzen Körper mit Ausnahme des Gesichts ohne Empfindung für Temperaturunterschiede, und ohne Schmerzempfindung.

Die Kranke stirbt am 13. Juni 1881 in der geburtshülflichen Klinik, nachdem sie einige Zeit vorher ein todtes Kind geboren.

Die Section (Prof. Arnold) ergab: chronische Bronchopneumonie; Peribronchitis, Bronchitis und Bronchectasien; ferner tuberculöse Ulcera des Darmes mit Perforation; tuberculöse Peritonitis.

Im Gebirne keine gröberen Veränderungen; dagegen ist das Rückenmark a ufallend platt und enthält einen weiten Kanal.

Die nähere von mir vorgenommene Untersuchung ergab im mittleren and unteren Lendentheil eìne grosse Höhle im Wesentlichen in den Hintersträngen, welche die umliegende Rückenmarkssubstanz auseinanderdrängt, und sich allmählich verjüngend und verkleinernd bis in den Conus terminalis hineinerstreckt.

Im Conus terminalis liegt der Centralkanal an normaler Stelle und ist obliterirt; weiter nach oben zu wird er durch einen seitlich verschobenen Zellenhaufen angedeutet. Die Höble selbst besitzt am gehärteten Präparate in der Mitte der Lendenanschwellung in ihrer stärksten Ausdehnung einen frontalen Durchmesser von $9 \mathrm{Mm}$., also nahezu $1 \mathrm{Cm}$., und einen sagittalen Durchmesser von $7 \mathrm{Mm}$. Sie hat ausser den vorderen Abschnitten der Hinterstränge auch das ganze linke Hinterhorn zerstört; ihre sehr zellenreiche Umgebung wuchert noch in die hinteren $\mathbf{A b}$ schnitte des linken Vorderhorns, weniger stark des rechten hinein, lässt aber die grossen Ganglienzellen derselben intact. In der Mitte der Vorderhörner, besonders des rechten, zeigt sich die Nervensubstanz etwas rareficirt; eine grössere Menge 
weit von einander entfernter Gliazellen und abnorme Mengen von zum Theil sclerosirten Capillargefässen zeigen sich dort. Die unmittelbare Grenze der Höhle wird durch keine eigentliche Membran, keine Anhäufung von welligem Bindegewebe, sondern einfach von Gliagewebe gebildet, dessen Fasern frei in das Lumen des Hohlraums hineinragen.

Im oberen Drittel der Lendenanschwellung und im Uebergangstheil zum Dorsaltheil wird die Höhle kleiner und beschränkt sich nur anf das linke Hinterhorn (Fig. 6); die Wandungen derselben klaffen an einigen Stellen nur wenig, so dass man nur noch von einem Spalte reden kann.

Dabei liegt der obliterirte Centralkanal wieder an seiner normalen Stelle; in seiner Umgebung lässt sich so wenig wie im Conus terminalis eine abnorme Zellenwucherung bemerken.

Die Wandung der Höhle wird hler dureh grobwelliges, dünnfasriges, fast kernloses, sich schwach in Carmin tingirendes Bindegewebe gebildet, nnter welchem sich das gewöhnliche Gliagewebe in dichten Fasermassen papillenartig vorwölbt.

In den Vorderhörnern, besonders im rechten zeigt sich das gleiche Bild wle weiter unten; die Seitenstränge und die Hinterstränge sind wie im ganzen Lendentheile - bis auf die zerstörten Abschnitte der letzteren - ganz normal; auch die hinteren inneren Wurzelfasern, welche zu dem zerstörten Hinterhorne sich hinziehen, erscheinen intact; ich fand nur hier und da einen gequollenen Axencylinder in denselben.

Im ganzen Dorsaltheil ziebt sich die Höhle wieder mehr in die Breite, wird mebr spaltförmig und nimmt die Form der Fig. 7 an; das Rückenmark wird ebenfalls stark in die Breite gezogen und erhält dadurch eine ganz ungewöhnliche Gestalt. Das linke Hinterhorn ist völlig in die Höhle mit ibrer sie umgebenden zellenreichen Gliawucherung aufgegangen, das rechte Hinterhorn weniger, in verschiedener Höhe in verschieden ansgedehnter Weise.

Der hintere Thell der Vorderhörner wird ebenfalls von Gliamassen eingenommen; nur die vordere Spitze derselben mit ibren Ganglien und vorderen Wurzelfasern bleiht intact. Der obliterirte Cientralkanal liegt etwas seitlich verschoben stets vor der Höhle.

Nach dem Halstheile zu wird die Form der Höble wieder complicirter; sie bekommt noch einen Recessus in das rechte Hinterhorn hinein, so dass hier beide Hinterhörner zerstört sind; an ihren äusseren Grenzen, nach den Seltensträngen zu, ziehen langgestreckte, leicht geschwungene, z. Th. sclerosirte Blutgefässe.

Im unteren Theile der Halsanschwellung tritt dann eine Zweitheilung der Höhle auf, indem noch ein Stück des Hinterstranges mit gewucherter Glia mit dem mittleren Theile der binteren Commissur in Verbindung bleibt; dabei geht aber die Höhlung mehr in belde Vorderhörner hinein, besonders in das linke. Dasselbe zeigt sich von vielen Spalten durchsetzt und wie zerfetzt, in schiefer Richtung von vorn nach hinten von denselben durchzogen und zwar so, dass die vorderen Enden der Spalten mehr medtanwärts, die hinteren mehr lateralwärts liegen.

Bald aber wird auch das rechte Vorderhorn fast ganz in einen Hohlraum umgewandelt, und es kommen dann ähnliche Bilder wie in Fig. 8 zu Stande. Beide Höhlen in der linken und rechten grauen Substanz sind durch einen queren, dle 
hintere Commissur und die angrenzenden vorderen Abschnitte der Hinterstrănge einnehmenden Querspalt mit einander verbunden; die Grenzen der Höhlen in den Vorderhörnern sind nahezu, und an einigen Stellen völlig die Grenzen der Vorderhörner selbst. An der Grenze des rechten Vorderhorns läuft die zellenreiche Gliamasse als Grenzschicht der Höhle entlang; in dem linken Vorderhorn finden sich noch restirende Ganglienzellen. - An anderen Begrenzungsstellen der Höhlen ist der einfassende Saum von Gliazellen ganz schmal oder fehit sogar völlig. In der Spitze des rechten Hinterhorns reicht die Höhlung bis an die Pia selbst, welche in der Breite von etwa 1-2 Mm. den Hohlraum überbrückt. Es erscheint der rechte Seitenstrang dadurcb völlig von den Hintersträngen abgetrennt. - Die Formveränderung und theilweise Einschrumpfung der einzelnen Rückenmarksabschnitte brauche ich nicht näher zu schildern; ein Blick auf die erwähnte Figur lässt dieselbe erkennen.

Die vorderen intramedullären Wurzeln sind besonders in den linken Vordersträngen zum grossen Theile völlig atrophisch, nur aus Bindegewehe bestehend; der extramedulläre Theil derselben im ganzen Halstbeil erscheint schon makroskopisch dünn und atrophisch, während die hinteren Wurzeln in normaler Dicke aus dem Rückenmarke hervorziehen, auf beiden Seiten ganz gleichmässig kräftig entwickelt.

Der Centralkanal hat sich inmitten der ausgedehnten Zerstörnng erbalten; er hat sich geöffnet, und liegt in normaler Grösse mit Epithel bekleidet an normaler Stelle.

In der Höhe der Pyramiàenkreuzong zelgt sich eine mit Gliamasse zum Theile ausgefüllte Höble, welche in der Nähe des Centralkanals liegt und die vordere Hälfte der Rolando'schen Substanz (der aufsteigenden Trigeminuswurzel) und einen Theil des Kerns der Seitenstränge einnimmt.

(Im Uebergangstheil zar Medulla oblongata fehlt ein kleines Stück des Präparats.)

Oberbalb der Pyramidenkreuzung an der unteren Hälfte der Medulla oblongata zeigen sich zwei eigenthümliche Veränderungen; nehmlich erstens eine Spalt bildung ganz ähnlich wie in Fall I und zweitens eine Sclerose und Atrophie des grössten Theiles der linken 0live, der inneren Nebenolive und des zwischen beiden genannten Theilen und der Raphe gelegenen Bezirks der reticularen Substanz.

Was zuerst deo Spalt betriff, so geht derselbe auf der rechten Seite neben dem Centralkanal, der hier sich noch nlcht in den vierten Ventrikel geöffnet hat, von dem Ependym aus, dieses intact lassend, und zieht nach aussen von dem Hypoglossuskern schräg nach vorn und aussen (ganz analog wie in Fall I), etwa der Richtung der Yagusfasern entsprechend, bis tief in die Substanz der Med. oblong. hinein. Er ist von zellenreichen Gliamassen in schmalem Sanme zu beiden Seiten eingefasst und hängt direct nach unten mit der beschriebenen Höhle der Pyramidenkreuzung zusammen, welche ibrerseits die Fortsetzung der Spaltbildung und Gliawucherung in Halstheile darstellt.

Die sclerotische Partie in der linken Olive nimmt etwa das untere Drittel derselben ein, diejenige der angrenzenden Schleifenschicht erstreckt sich bis zum oberen Ende des Olivarkörpers, ist aber unten stärker als oben. Es bandelt sich 
in der letzteren um eine Atrophie der Nervenfasern mit geringer Vermehrung der Glia. Die Ganglienzellen der Olive sind stark verkleinert and an Zahl vermindert. Durch die von der Atrophie herbeigefübrte Schrumpfung ist die Raphe nach der kranken Sette herübergezogen; die atrophische Stelle schon durch die stärkere Carminfärbung makroskopisch kenntlich.

Oberhalb der Olivenkörper zeigt sich die Medulla oblongata normal.

\section{Beobachtung V.}

Amyotrophische Lateralsclerose. - Ausgedehotes Gliom des Rïckenmarks. Syringomyelie.

Krankengeschichte ${ }^{1}$ ): v. S., 17 Jahre alt, hat von frühster Kindheit auf Schwäche, Abmagerung und Verkürzung des rechten Fusses gebabt, welche onbemerkt entstand and nicht wie bei spinaler Kinderlähmung in Scene trat. Später ist er als Knabe mit Hülfe einer Maschine ganz gut gelaufen. Sonst kräftig entwickelte Muskeln.

Im 15. Lebensjahre, steifer Hals", Scbmerzhaftigkeit und Steifheit des Nackens, keine ausstrahlenden Schmerzen in die Schultern und Arme. Die Nackenschmerzen waren noch nicht völlig geschwunden, wenn auch verringert, als $\frac{1}{4}$ Jahr später zunehmende Schwäche in allen Gliedern ohne Parästhesien eintrat. Während nun gymnastische Uebungen vorgenommen wurden, steigerte sich die Schwäche bis fast zur Lähmung und ausserdem stellte sich hochgradige $\mathbf{A b}$ magerung der Arme und Hände neben Spannungsgefübl and krampfhaften Ziehen in beiden Beinen ein.

Nie Kopfschmerz; Anfang December 1876 leichte Blasenschwäche. Der am 10. December 1876 aufgenommene $S t a t$. praes. ergab bei dem 15 jährigen Knaben :

Am rechten Beine hochgradiger Pes calcaneus; die Wadenmuskeln sind völlig atrophiscb, gelähmt, zum grössten Theil in Fettgewebe verwandelt. Peroneusgebiet mässig atrophisch und paretiseh. Unterschenkel etwas verkürzt. Oberschenkel deotlich paretisch; seine Musculatur von normaler Festigkeit.

Linkes Bein paretisch, aber obne Atrophie.

Sehnenreflexe beiderseits gesteigert, Hautreflexe normal. Tastempfindung rechts etwas abgestumpft.

Aufsitzen numöglich.

Beide Arme und Hände hochgradig paretisch and atrophisch; charakteristische Krallenstellung der Finger.

Die Muskeln der Arme und Hănde zeigen bei galvanischer Reizung ausgesprochen träge, tonische Zuckung, vom Nerven aus blitzähnliche Zusammenziehungen (partielle Entartungsreaction). Die mechanische Erregbarkett hocbgradig gesteigert. Sehnenreflexe fehlen. Kei ne Spur ron subjectiver und objectiver Sensibilitätsstörung.

Schulter- und Rückenmoskeln nicht deutlich atrophisch. Halswirbelsäule steif;

1) Die Krankengeschichte dieses Falles rührt von Herrn Prof. Erb her, welcher diesen Fall in sejnem Handbuche der Räckenmarkskrankheiten (S. 727 Anmerk, I und Text) erwähnt. 
Druck auf den 3. bis 5. Halswirbel empfindlich. - Gesichtsnerven, Bulbärnerven intact.

Măr 1877 ist die Parese der oberen Extremitaten in eine Paralyse übergegangen; die Atrophie derselben ist ganz hochgradig. Die Haut der Hände livid, gedunsen, mit dunklen Flecken wie mit Frostbenlen bedeckt. Keine Contracturen. Tast- und Temperaturempfindung normal; leichte Analgesie.

Die electrische Untersuchung ergiebt die faradische Erregbarkeit der Nerven nd Muskeln erhalten, etwas herabgesetzt; die galvanische Erregbarkeit der Nerven erbalten und qualitativ normal, diejenige der Muskeln dagegen erhöht und wie oben angegeben verändert. (Geprüft wurden der Medianus, Ulnaris und Radialis.) An den Unterextremitaten verhält sich die electrische Erregbarkeit normal; in den Muskeln ist jetzt deutliche Spannung eingetreten; öfters erscheinen spontane Zuckungen derselben. Die Sensibilität ist normal. - Harnentleerung verlangsamt. - Keine bulbären Symptome. Die linke Pupille weiter als die rechte. -

Im Laufe der nächsten Monate gesellt sich mässige Extensionscontractur in den Ellenbogengelenken dazu, die ganzen Oberextremitäten werden gestreckt und liegen dem Rumpfe an; die Hände stellen sich in Dorsalfexion. Die Motilität einzelner Muskeln ist eln wenig besser. Die trophischen Störungen der Haut gemindert; indessen fallen an der linken Hand einige Fingernägel $a b$. Hier und da Schmerz in der Nackengegend. Die linke Pupille wie früher; Hirnnerven bleiben frei. - Die electrische Erregbarkeit wird im August noch einmal gepruft; sie ergiebt dasselbe Resultat wie früher.

Im 0 ct ober 1877 lässt sich eine geringfügige Besserung der Beweglichkeit in beiden Radialisgebieten constatiren; sonst vollkommener Status idem. Parese des linken Abducens. Die Pupillen wieder normal, reagiren gut. Die linke Seite der Halswirbelsänle stärker vorgewölbt, "als ob ein kleiner Tumor dahinter sässe". Dornfortsätze nicht sehr empindlich.

Im December vorübergehend B lasenscbwäcbe. Sonst bis zum letalen Ausgange keine neuen weiteren Symptome. Den Schluss der Krankheit bildeten pnenmonische Erscheinungen mit starker Athemnoth. Der Tod erfolgte am 26. April 1878.

Die Section des Rückenmarks wurde von mir rorgenommen. Wegen der grossen Eile, in welcher dieselbe im Privathause gemacht werden musste, ist sie nicht ganz vollständig; ich erhielt die untere Hälfte der Lendenanschwellung nicht.

Es fiel bei der Herausnahme des Rückenmarks auf, dass eine colossale Tumorbildung im ganzen Hals- und Dorsaltheile statthatte, der Art, dass im Halstheil der ganze Wirbelkanal völlig ausgefüllt wurde und die in gewöhnlicher Distanz von einander befestigten Blätter der Rückenwirbelsäge in einer Höhe von ein paar Zoll ein Stück des Tumors seitlich abspalteten. Die Grösse des Tumors war noch erheblicher als in einem früher von mir geschilderten analogen Falle (Archiv f. Psychiatrie Bd. VIII. Heft 2).

Ausserdem zeigten sich im Dorsaltheile verschleden gestaltete Spalten und Höhlen in der spinalen Substanz.

Die genauere Untersuchung lehrt, dass schon der obere Thetl der Lendenanschwellung ein abnormes Volumen hat, ohne dass in demselben sich Höblen gefunden bätten. Der sagittale Durchmesser beträgt $1,1 \mathrm{~cm}$., der frontale etwa 
$1 \mathrm{Cm}$. - Dabei erscheint das rechte Vorderhorn noch voluminöser als das linke, und ausserdem ist der ganze Rayon der vorderen zwei Drittel beider Hinterstränge in der Müller'schen Flüssigkeit gelblich verfärbt. Mikroskopisch zelgt sich besonders diese oben genannte Partie, dann aber a uch di e gesammte graue Substanz und zum grössten Theile auch die Seitenstränge, wenn auch in geringerem Maasse, von colossalen Deiters'schen Zellen dicht durchsetzt, welche oft fast einen Zellenkörper von der Grösse einer mittelgrossen multipolaren Vorderbornganglienzelle besitzen und mit vielfachen, dicken und langen Fortsätzen versehen sind. In der weissen Substanz liegen sie besonders in den Kreuzungspunkten der Gliafasern, zwischen sich intacte Nervenfasern lassend; in der grauen Substanz beherrschen sie fast den ganzen Querschnitt; nur an der nach vorn gerichteten Spitze der Vorderbörner finden sich intacte Ganglienzellen. - Der Centralkanal liegt an normaler Stelle, ist offen, normal gross and mit Epithel bekleidet. -

Im Uebergangstheile zum Dorsaltheile zelgt sich in der Mitte der verfärbten Partie der Hinterstränge - in welcher die Gliose besonders stark entwickelt ist - und 2war mehr nach der Commissur hin als nach der hinteren Peripherie zu gelegen, eine weichere Stelle, die allmählich weiter nach oben zu der Bildung einer kleinen unregeimässigen Höhle führt, deren Wand mit Glialamellen und Gliabalken ausgekleidet ist. Weiter aufwärts zieht sich diese Höhle, die nunmebr glattwandig wird, in das rechte Hinterhorn hinein, und wird dann zu einem längsgezogenen, in der Richtung des Hinterhorns dahinziehenden Spalt, der bald mehr, bald weniger klafft und bis an die Spitze des Hinterhorns reicht. Der Centralkanal liegt offen, an einzelnen Stellen obliterirt, an normaler Stelle, vor der gliomatösen Masse. Die Durchsetzung der grauen Substanz und der Hinterstränge mittelst Deiters'scher Zellen wie im Lendentheil; dle Pybahnen des rechten Sèitenstranges degenerirt; links nicht deutlich.

Im mittleren Abschnitte des Dorsaltbells, welcher um mehrals das Doppelte in allen Durchmessern vergrössert ist, wird die Spaltbildung ausgedehnter; sie geht auch nach rechts in die Basis des rechten Hinterborns binüber und nimmt auf den verschiedenen Querschnittshöhen rasch wechselnd verschiedene Gestaltung an, deren nähere Beschreibung kein Interesse bietet. Der Spalt klafft nur wenig; der Centralkanal ist obliterirt und liegt an normaler Stelle. Die Auskleidung des Spaltes geschieht durch zahlreich angehäufte Gliazellen, mit welchen das benachbarte Gewebe ebenfalls stark durchsetzt ist; nirgends Epithel.

Die enorme Volumensvermebrung des Rückenmarks wird besonders durch die Gliawucherung in den Hintersträngen, dann aber auch durch die erbebliche Vermehrung der Deiters'schen Zellen in den Vorderhörnern und Seitensträngen bewirkt. In allen restirenden Abschnitten der weissen Substanz finden sich zahlreiche mässig stark gequollene Axencylinder.

Etwa in der Mitte des Dorsaltheiles schwinden die Spalten völlig; die centrale Tumormasse wird viel massiger, ist auf dem Querschnitte ganz glatt, an einzelnen Stellen schwach röthlich gefärbt und drängt die Vorder-, Seiten- und Hinterstrầnge ganz an die Peripherie, so dass sie die Gliommasse mantelförmig umgeben.

Am stärksten entwickelt zeigt sich das Gliom im ganzen Halstheile, nach der Medulla oblongata zu an Volumen abnehmend; aber immer sieht man noch 
Reste der vorderen grauen Substanz und der Vorderseitenstränge stehen bleiben. Die Hinterstrănge sind am meisten zusammengedrängt und reducirt.

An einigen Stellen, an denen bel dem frischen Rückenmarke Querschnitte angelegt wurden, hat sich die weisse Substanz völlig von den centralen Gliommassen abgehoben und manchettenartig umgehogen, so dass es fast so erscheint, als ob hier eine vollständige Continuitätsunterbrecbung der weissen Substanz vorbanden wäre. Das ist aber nirgends der Fall.

Ehe sich dicht unterhalb der Pyramidenkreuzung die gliomatöse Wucherung auf die Gegend hinter der. hinteren Commissur beschränkt, wuchert sie noch pilzförmig an der Peripherie der Hinterstrănge nach hinten zu heraus und verleiht dadurch der Form der Medulla spinalis ein eigenthümliches Aussehen.

In der Gegend der Pyramidenkreuzung und in der unteren Partie der Medulla oblongata bis etwa zur Höhe der unteren Partie der Hypoglossuskerne beschränkt sich das Gliom auf eine Gliawucherung rings um den Centralkanal, die benachbarten grauen Kerne daselbst mit Gliazellen in abnormer Menge durchsetzend. Die oberen Abschnitte der Medulla oblongata fehlen leider. -

Die Gliommasse ist an verschiedenen Stellen weicher, zerfliesslicher, theilweise von Hämorrhagien durchsetzt; grössere Spalt- und Höblenbildung innerbalb desselben findet sich nicht; nur kleinere Lücken, welche von erweichter Substanz umgeben sind, lassen sich finden.

Der Centralkanal ist im Halstheile verschwunden, in die Gliommassen aufgegangen; im unteren Abschnitte der Medulla oblongata erscheint er wieder normal weit, geöffnet und mit Epithelzellen ausgekleidet, communicirt nirgends im ganzen Rückenmarke mit den vorhandenen Spalten. -

Histologisch betrachtet besteht das Gliom wesentlich aus Zellen von dem Charakter der centralen Ependymzellen; an den meisten Stellen ist eine Anhäufung derselben in Nesterform vorhanden, in welcher sie dicht gedrängt neben einander liegen. Zwischen diesen Nestern liegt dann gewöhnlich fasriges Gliagewebe mit spärlichen Zellen. An der erwähnten Stelle der pilzförmigen Wucherung in den Hintersträngen des Halstheils ist die Structur eine andere. Man sieht auf dem Querschnitte anstatt querdurchschnittener Nervenfasern in den hinteren Abschnitten der Hinterstränge Längsz üge von Nervenfasern in der Richtung der hinteren Wurzelbündel und der hinteren Wurzeln dahinziehen, welche durch abnorm grosse Mengen von Gliafasern in welligen Zügen von einander getrennt sind. Die Zahl der Zellen ist hier eine viel geringere als in der eigentlichen Gliommasse; ob die Nervenfasern an Zahl vermehrt sind, lässt sich nicht entscheiden.

Die vorderen Wurzeln im ganzen Halstheile sind stark abgeplattet und viel dünner, führen aber noch normale Fasern in grösserer Menge; die hinteren Wurzeln desgleichen.

Die angeführten Beobachtungen zeigen zunächst, dass sich überall ausser den Spalten und Höhlen selbst noch anderweitige Veränderungen finden, dass sich Wucherung und Vermehrung der Glia und in einzelnen Fällen eine reine Gliomatose, eine Gliombildung neben denselben zeigt. 
Ein derartiges Zusammentreffen kann unmöglich ein zufälliges sein; denn in allen sonst in der Literatur bekannten Fällen verhielt sich die Sache ebenso. Nur bei Langhans (a. a. 0.) ist in der Beschreibung seiner Fälle mit geringer Betonung von dieser Gliavermehrung gesprochen; sie war nur in geringem Grade vorhanden. Bei diesem Autor wird der Hauptnachdruck stets auf ein sonst nicht in gleicher Weise beobachtetes 0edem gelegt, welches auch die in seiner Fig. II vorhandene starke Schrumpfung der Hinterstränge erkJären soll.

Es ist richtig, die Gliawucherung in der Nähe und in weiterer Entfernung von den Spalten kann an Extensität in den einzelnen Fällen sehr wechseln, sogar in einem und demselben Falle (wie z. B. die Beobachtung I ergiebt) an Ausdehnung recht versebieden sein und dadurch leicht als etwas Nebensächliches erscheinen; sie ist es aber keineswegs, wie die späteren Erörterungen hoffentlicb beweisen werden.

Fernerhin steht die Gliawucherung meistentheils in inniger Beziehung zu demjenigen Gewebe, welches den bei älteren Individuen fast regelmässig obliterirten Centralkanal umgiebt, zu dem sogenannten Ependym. Von ihm geht die Zellen- und Faserwucherung gewöhnlich aus; dieselben Zellenformen, dieselbe Anordnung dieser Zellen zu den Gliafasern, wie sie sich in ihm zeigen, finden sich, wie oben ausführlicher geschildert, in seiner nächsten Umgebung, in der hinteren und vorderen Commissur, in den Hintersträngen und in der grauen Substanz. Aber keineswegs ausschliesslich ist das Ependym der Mutterboden der wuchernden Gliazellen; auch die graue Substanz der Hinterhörner kann, wie Leyden mit Recht hervorhebt, den Ausgangspunkt darstellen, vielleicht auch manchmal die weisse Substanz, und auch in diesem Gewebe können Spalten entstehen, welche wie in Fall Il nirgends mit dem Centralkanal oder einem Divertikel desselben oder mit dem Ependym zusammenhängen.

Wie aber sind, und damit komme ich zu der Hauptfrage, diese Spalten und Höhlen in den obigen und in den sonst beschriebenen Fällen zu dẹuten?

Für einen grossen Theil derselben lässt sich direct zeigen, dass sie durch Zerfall der gewucherten Glia entstehen. Schon makroskopisch sieht man nicht selten das neugebildete Gewebe irgendwo weich, gelockert, graulich verfärbt, gallertig und mikroskopisch kann 
man an lückenlosen Schnittserien eine immer weiter gebende Rarefication der Zellen und Fasern deutlich verfolgen. Schliesslich giebt es dann einen völligen Substanzverlust, und die Höhle ist da. Diese Höhle kann einfach von Glia umgeben sein oder nicht selten von einem wellig geformten Bindegewebe, welches übrigens mit der eigentlichen Glia völlig gleichartig ist. Dass dasselbe durchaus nicht immer secundär nach der Vollendung der Cystenbildung sich entwickeln braucht, sondern dass es inmitten der gewöhnlichen Gliawucherung sich bildet und erst weiterhin in ihm Spaltbildung entstehen kann, erscheint nach dem Obigen kaum zweifelhaft.

Welcher Art die geschilderte Erweichung ist, ob z. B. eine schleimige Umwandlung vorliegt, lässt sich nicht ausmachen; für eine fettige Degeneration liess sich in den obigen Fällen der Nachweis nicht erbringen. Aber an dem Factum des Zerfalles selbst lässt sich nicht zweifeln; fast alle Autoren, die sich mit der Frage beschäftigten, besonders auch Leyden, haben es durchaus anerkannt. Man hat sich nur an der eigenthümlichen Lage und Form der Höhlen, die sich mit so besonderer Vorliebe in den vorderen Abschnitten der Hinterstränge finden, gestossen und daraus weitere Schläisse gezogen. -

Langhans vermisst überdies alle Analogie mit ähnlichen Prozessen im Gehirn und behauptet, dass gliomatöse Geschwülste in den genannten Abschnitten der Hinterstränge ohne jene eigenthümliche Erweichung, welche den grössten Theil derselben zerstört und nur peripherische Reste übrig lässt, nicht beobachtet seien.

Dagegen ist zu sagen, dass ausgedehnte Erweichungsprozesse bei Gliomen im Gehirn nicht so selten sind, und dass auch im Rückenmarke die centrale Wucherung hinter dem Centralkanal sowobl bei grosser als geringer Massenentwickelung derselben auf lange Strecken hin ohne Spaltbildung bleiben kann wie z. B. in Fall I u. V. Freilich fehlı die Höhlenbildung wohl kaum völlig; aber ebensowenig fehlt sie in allen jenen Fällen von enormer spinaler Gliombildung, welche ganz gewiss und unzweifelhaft eine Geschwulstneubildung mit allen Charakteren einer solchen darstellt. Zwischen diesen Gliomen aber und jenen geringfügigeren Wucherungen ependymärer Glia sind, wie die Vergleichung der obigen Fälle auf das klarste lehrt, nur gradweise, quantitative Verschiedenheiten vorhanden, aber keine qualitativen. An einem und demselben 
Präpara te kann man die verschiedenen Uebergangsstadien studiren; und die Spalt- and Höhlenbildung ist bei den Gliomen sowobl als bei den sogenannten periependymären Sclerosen ausserordentlich different je nach der Beschaffenheit des leichter oder schwerer erweichenden Gewebes, so dass einmal wie partiell im Falle $I$ und in ausgedehnterem Maasse in der Beobachtung IV nur sehr geringe, fast verschwindende Mengen von Glia die Höhlen umgeben, das andere Mal, wie z. B. in einer andern Höhenausdehnung des schon genannten Falles I oder in dem Falle II die umgebende Wucherungsmasse beträchtlich ist. Ich will das nicht bis in das EinzeJne durchgehen; wer sich die Mühe nimmt, die Schilderung der obigen Beobachtungen genauer zu lesen, wird die Wahrheit des Gesagten sicherlich zugeben.

Wenn nun aber einerseits zugegeben wird und zugegeben werden muss, dass überhaupt centraler Zerfall eintreten kann und andererseits, dass das Ependym meistentheils den Mutterboden der geschilderten Wucherungsprozesse darstellt, wie ist es da so sehr verwunderlich, dass auch die entstehende Neubildung sich ganz analog wie in anderen ähnlichen Fällen der Gestalt ihrer Matrix anschliesst, dass sie lang hingestreckt erscheint und ibre centralen Spalten oft eine stattliche Längsausdehnung einnebmen?

Zudem ist es nicht richtig, dass nur die vorderen Partien der Hinterstränge der Sitz der Spaltbildung zu sein brauchen; abgesehen von den Hinterhörnern können, wie wir sahen, auch die Vorderhörner, ferner die Seitenstränge und selbst gewisse Partien der Medulla oblongata durch die Spaltbildung getroffen werden, was bisher in dieser Weise noch nicht bekannt war. Es ist also die Variabilität des Sitzes der Höhlenbildung eine viel grössere als man bisher wusste, und unmöglich kann somit die Lagerungsweise der Spalten allein als ein Grund gegen die Entstehung derselben durch secundäre Erweichungsprozesse fernerhin noch angeführt werden.

Wie steht es nun aber mit den sonst aufgestellten und in der Einleitung kurz skizzirten Hypothesen über die Genese der Höhlenbildungen?

Langhans will, wie erwähnt, ein Stauungsödem als Ursache angenommen wissen, welches seinerseits in einem gesteigerten intracraniellen Drucke in der hinteren Schädelgrube seinen Grund finden 
soll. Abgesehen davon, dass in den allermeisten bekannten Fällen von Syringomyelie und auch in mehreren der oben geschilderten von einem gesteigerten Hirndrucke keine Rede war und ferner abgesehen davon, dass in vielen Fällen von Hirntumor in der hinteren Schädelgruppe keine Spur von Spaltbildung im Rückenmarke gefunden wurde, bleibt, wie Langhans selbst zugiebt, die Frage unbeantwortet, warum der Abfluss des Blutes und der Lymphe im Halsund Dorsaltheile der Medulla spinalis nicht durch die vielen direeten Communicationswege unterbalb des Schädels vermittelst der spinalen Venen und derjenigen Lymphbahnen, welche mit den Nervenwurzeln den Spinalkanal verlassen, geschehen sollte. Warum entsteht, falls die Langhans'sche Auffassung richtig wäre, nicht wenigstens in einem oder dem anderen Falle von Compressionsmyelitis des Halsoder Dorsaltheiles in den darunter gelegenen Abschnitten des Rückenmarkes eine derartige Spaltbildung? Freilich soll die Langhans'sche Hypothese hauptsächlich nur für diejenigen Fälle gelten, bei welchen neben der Tumorbildung in der hinteren Schädelgrube noch Divertikelbildungen des Centralkanales mit der Richtung nach abwärts sich vorfinden, welche ihrerseits durch den gesteigerten Druck der spinalen Flüssigkeit zu Stande gebracht werden sollen. Aber es fehlt auch für diese Fälle jeder Anhaltspunkt dafür, dass der Abfluss des Blutes und der Lymphe im Rückenmarke nach den Seiten des Wirbelkanales hin oder nach abwärts zu irgendwie erschwerter war als in den anderen Fällen. Und was die Divertikelbildung anbetrifft, so ist es ja vielleicht möglich, dass sie durch Druck zu Stande kommen kann, aber sie kann doch nicht schon als Beweis für den angenommenen Druck herbeigezogen werden, zumal sie auf andere Weise sich einfacher erklären lässt. -

Was nun weiter die zweite der oben genannten Hypothesen uber die Syringomyelie anbetrifft, welche von Leyden herrührt, der sie auf Entwicklungsanomalien der Centralkanalbildung zurückführt, so babe ich diese selber in einem früher publicirten Aufsatze über einen Fall von Rückenmarkstumor (Westphal's Archiv Bd. VIII Heft 2) für den betreffenden Fall als die wahrscheinlich richtige acceptirt und mich auch später in einem ähnlichen Sinne ausgesprochen. Angesichts der oben beschriebenen neuen Befunde erscheint es aber unmöglich, sie für alle Fälle aufrecht zu erhalten.

So lange man es nur mit Hohlraumbildung in den Hinter- 
strängen allein zu thun hat, lässt sich ja ganz gut vorstellen, dass ein unvollständig geschlossener Centralkanal zu der Defectbildung und zu secundärer Wucherung in der Wand desselben führt. Wenn aber die Spalten in den Hinterhörnern, oder gar in den Seitensträngen und in den Vorderhörnern der Medulla oblongata liegen, so ist, falls sonstige Difformitäten besonders der grauen Sub$\operatorname{stanz}$ fehlen, nicht denkbar, dass der Centralkanal, an dessen Aussenseite sich die grave Substanz der Hinterbörner doch regulärer Weise bildet, z. B. nach aussen von den Hinterhörnern oder einem Theile derselben zu liegen kommt. Auch die Spaltbildung in der Medulla oblongata, wie sie sich in ziemlich gleichartiger Weise in zweien der obigen Fälle constatiren liess, ist entwicklungsgeschichtlich durch Abnormitäten in der Entwicklung des 4. Ventrikels nicht erklärlich. Aber wenn wie in dem eigenthümlichen Falle III derartige Entwicklungsanomalien vorbanden sind, dass z. B. die graue Vorderhornsubstanz zum grossen Theil hinter den abnorm breiten Centralkanal zu liegen kommt, so muss angenommen werden, dass auch ursprünglich die erste Anlage der vorderen grauen Substanz weiter nach binten zu sich entwickelt hat als gewöbnlich; und für solche und ähnliche Fälle liesse sich demnach die Leyden'sche Auffassung durchaus festhalten.

Natürlich kann auch eine Combination zwischen angebornen Anomalien und später entstehenden Spaltbildungen sich vorfinden, welche dann die richtige Beurtheilung sehr erschwert.

In dem letztgenannten Falle z. B. lässt es sich unmöglich ausmachen, ob nicht ein Theil der Spalte, welche sich bis tief in die Hinterhornsubstanz hineinerstreckte und kein Gylinderepithel mehr führte, nachträglich durch Zerfall entstanden ist oder nicht. Den mit Cylinderepithel bekleideten Theil des Spaltes muss man wohl als erweiterten Kanal gelten lassen, wenn man nicht annehmen will, dass auch in die neugebildeten Höhlen hinein sich die Epithelbekleidung von den ursprünglichen Epithelzellen aus fortpflanzen könnte.

Die Hauptsache ist die, dass ganz unzweifelhaft normal gebaute Rückenmarke Erwachsener existiren, bei denen irreguläre Spalten ausserhalb des Hinterstrangrayons vorkommen, bei denen ausserdem die klinischen Symptome erweisen, dass die Destructionen mindestens zum grössten Theil im späteren Leben eintreten, und in denen schliesslich direct der Zerfall ependymärer Gliamassen ge- 
sehen und nachgewiesen werden kann. Für diese Fälle, wie in Beobachlung $I$ und IV ist die Spaltbildung eine secundäre, eine erworbene; sie sind Beispiele echter Syringom yelie in dem Simon'schen Sinne. Auch bei den Fällen colossaler Gliome lässt sich eine secundäre Höhlenbildung durch Zerfall nicht von der Hand weisen.

Es giebt dann andere Beobachtungen, wie die von Leyden selbst publicirten (d. Arch. Bd. 68), in welchen bei Kindern sich innerhalb des Hinterstrangrayons Defecte finden, in denen die Form der vorhandenen, in weiter Ausdebnung mit Epithel ausgekleideten Höhlen eine etwas andere ist als gewöhnlich, nehmlich auf dem Qnerschnitte mit dem längsten Durchmesser von hinten nach vorn gerichtet, während sonst derselbe bei der Syringomyelie gewöhnlich mehr in frontale Richtung zu liegen kommt. Dabei ist zugleich eine kümmerliche Entwicklung der Hinterstränge vorhanden, welche in den sonstigen Fällen fehlt. Für diese Fälle ist an der Annahme einer congenitalen Defectbildung, eines Hydromyelus festzuhalten.

Sind nun bei Erwachsenen Höhlen und Gliawucherung nur im Hinterstrangrayon vorhanden, so ist die Kategorie, in welche die Fälle gehören, schwer festzustellen, wie z. B. in der 2. mitgetheilten Beobachtung.

Sind entschiedene Abnormitäten des Centralkanales und des Aufbaus im Rückenmark vorhanden, wie im Falle III, so wird natürlich mit Sicherheit ein Theil der Veränderungen als congenital aufgefasst werden müssen, während über die Genese eines Theiles der Spalten nicht entschieden werden kann.

Ob vorhandene Abnormitäten der genannten Art zu später entstehenden weiteren Spaltbildungen, ferner zu Ependymwucherungen und zu Gliomen besonders disponiren, lässt sich bei der Geringfügigkeit des vorliegenden Materials noch nicht feststellen, erscheint aber durchaus wahrscheinlich. - So sicher es ist, dass kleinere Abweichungen im Bau des Centralkanales z. B. Verdoppelungen, oder auch Erweiterungen desselben bei intactem Rückenmark und intacten Functionen das Leben bindurch bestehen können, so sicher kann auch die gleiche Gliawucherung mit ibrer Tendenz zu Zerfall und also zu Spalt- und Höhlenbildung auch an dem ganz normal entwickelten Ependym entstehen. - 
Ich kann mich also nur gegen die Ausschliesslichkeit der Leyden'schen Anschauung, welche alle Fälle von Syringomyelie von Hydromyelus ableitet, nicht gegen ihre Berechtigung überhaupt wenden, wäbrend mir die Langhans'sche Aufstellung für alle bisher bekannten Fälle noch nicht hinreichend gestützt erscheint. - Warum freilich diejenigen Spalten, welche nach dem Obigen als secundäre angesehen werden müssen, vorzugsweise in den Hinterhörnern und in den beschriebenen Abschnitten der Med. oblong. sich befinden, ist schwer zu sagen. Sie finden sich gewöhnlich fast in ihrer ganzen Ausdehnung von en orm verdickten Gefässen durchsetzt und begrenzt, in deren Nähe eine grössere Lockerung des Gliagewebes mit Vorliebe stattfinden mag, wenn sie auch nicht immer zu völliger Spaltbildung führt (vgl. besonders Fall III). Diese Verdickung der Gefässe zeigt sich besonders gern in den Hinterhörnern. -

Wenden wir uns nunmehr zu dem Verhalten derjenigen Abschnitte des Rückenmarkes in den obigen Fällen, welche nicht direct von der Spaltbildung betroffen wurden, so sind besonders die begleitenden Degenerationen in den Seitensträngen, dann in den Hintersträngen und einmal in einer Olive bemerkenswerth. Die Uinterschiede zwischen den beschriebenen eigenthümlichen Gliawucherungen und sonstigen Prozessen in der Glia, welche ebenfalls mit der Vermehrung derselben einhergehen, sind in die Augen fallend. Zuerst ist bei der sogenannten "Sclerose" und besonders bei der multiplen Sclerose gewöhnlich die Zellenwucherung viel geringer, die einfache Fibrillenvermehrung überwiegt; das Vorhandensein von Körnchenzellen oder Corpora amylacea ist reichlicher. Dann aber fehlen immer die Verdrängungserscheinungen in dem umliegenden Gewebe und die Neigung zu Zerfall und Spaltbildung. Auch die Zustände der secundären Degeneration, bei welcher Hand in Hand mit zerfallenden Nerven die Gliavermehrung auftritt, und ebenso die systematischen Degenerationen z, B. die amyotrophische Lateralsclerose, bei denen eine primärc Atrophie der Nerven anzunehmen ist, führen entweder niemals oder höchst selten $z u$ Spaltbildungen oder gar zu Verdrängungserscheinungen. In einem Falle von Friedreich (Bd. XXVI und XXVII d. Arch.) in welchem combinirte Erkrankung von Hintersträngen und Seitensträngen bei hereditärer Ataxie vorhanden war, ist von einer Höhlenbildung in der Gegend der Hinterhörner die Rede. 
Es erscheint deswegen unpassend, die Wucherungen der ependymären Glia, wie sie in den obigen Fällen und in ähnlichen beobachtet wurden, nach Hallopeau mit dem Namen der periependymären "Sclerose" zu belegen. Man könnte entweder von Gliomatose sprechen, oder, da der Geschwulstcharakter der Veränderung oft nur angedeutet ist, so dass auch die Verdrängungserscheinungen noch fehlen, von einer Gliose reden, wobei zugleich durch diese Benennung die innige Beziehung zu der Gliombildung, deren geringste und geringe Grade sie darstellt, angedeutet werden soll. Man hätte demnach, wenn man alle Prozesse im centralen Nervensystem, welche mit Wucherung der Gliagewebes einhergehen, zusammenstellt, zuerst die Zustände des degenerativen Atrophie der Nervenfasern (bei secundären Degenerationen, bei systematischen Erkrankungen), bei welcher die Gliawucherung etwas secundäres, später erfolgendes darstellt. Zweitens die multiple Sclerose, bei welcher wahrscheinlich der Gefässbindegewebeapparat den Ausgangspunkt der Erkrankung bildet. Dann die Gliose, welche meistens von dem Ependyme, aber auch von der Rolando'schen Substanz und möglicherweise auch von anderen Abschnitten der Glia ausgeht, und die oben bezeichneten Charaktere hat. Endlich die Gliomatose und das Gliom, zu welcher die Gliose die Vorstufe bildet.

In diese Kategorie würde auch die sogenannte gliomatöse Hypertrophie gehören, bei welcher die Nervenfasern und die gewöhnliche Structur der betroffenen Abschnitte länger erhalten bleiben und bei der die Spaltbildung und der Zerfall gewöhnlich fehlt.

Wenn wirkliche Neubildung von Nervenfasern sich zu der Neubildung von Glia hinzugesellt, so sind diese Geschwülste wohl am besten mit dem Namen der Neurogliome (Klebs) zu bezeichnen.

Dass nun derartige Prozesse, welche in einer Wucherung der Glia ihre gemeinschaftliche Grundlage haben, sich mit einander an einem um demselben Präparate combiniren können, ist wohl selbstverständlich. Es wird sich immer um fliessende Grenzen zwischen ihnen handeln.

So geht in einem der obigen Fälle (III) direct von der gliösen Wucherung um den Centralkanal eine Vermehrung des Bindegewebes in der Nähe der binteren Fissur aus, welche im Halstheile mit einer 
Degeneration der Goll'schen Stränge verknüpft ist. Im Falle I ist eine directe Verbindung der ependymären Wucherungen mit einer Seitenstrangdegeneration vorhanden, welche sich in ihrem Aussehen von der gewöhnlichen Form derselben z. B. bei lange dauernden secundären Degenerationen nicht unterscheidet. Im Falle $V$ ist eine enorme Vermehrung der Deiters'schen Zellen in den Vorderhörnern neben und in unmittelbarem Zusammenhange mit dem Gliome, im Falle IV eine räumlich von der Gliose getrennte degenerative Atrophie einer Olive vorhanden. Im Falle $V$ ist ausserdem neben dem ependymären colossalen Gliom mit zellenreicher Structur eine gliomatöse Hypertrophie in den Hintersträngen und in den intramedullären hinteren Wurzeln zugegen. -

Was nun die klinischen Erschein ungen in den besprochenen Beobachtungen anlangt, so ist die Zurückführung derselben auf das anatomische Substrat und die Erklärung aus den Befunden keineswegs schwer. Es fragt sich nur, ob nicht für die Differentialdiagnose von anderweitigen spinalen Erkrankungen durch die geschilderten Symptome Anbaltspunkte gegeben sind.

Es ist von vornherein klar, dass eine mässig intensive Ependymwucherung mit Spaltbildung überhaupt keine Symptome zu machen braucht. Selbst in dem Falle III, wo neben diesen Abnormitäten noch eine Atrophie der vorderen grauen Substanz im Dorsalmarke zugegen war, liessen sich deulliche Zeichen einer spinalen Erkrankung trotz genauerer Untersuchung nicht finden. Es ist möglich und wahrscheinlich, dass eine mässige Atrophie der von den genannten Partien versorgten Muskeln sowohl bei Lebzeiten als bei der Section mir entgangen ist, zumal oft nur die mikroskopische Untersuchung in solchen Fällen Auskunft ertheilen kann. Immerhin waren die Rückenmuskeln makroskopisch intact; und in den vordern Wurzeln des Dorsaltheiles waren mikroskopisch grosse Mengen gesunder oder, besser gesagt, nicht nachweisbar kranker Nervenfasern zu finden. Die Lähmung in den Armnerven, welche bestand, hatte peripherischen Ursprang.

In dem ersten Falle lässt es sich auch nach der Section nicht mit Sicherbeit ausmachen, ob die vorhanden gewesene Contractur beider Unterextremitäten auf die Seitenstrangdegeneration, welche die Spaltbildung begleitete, oder auf die Gelenkaffection oder auf beide zugleich zu beziehen ist. Es wäre besonders interessant 
gewesen, über das Verhalten der Sensibilität in den letzten Minuten des Kranken näheres zu wissen, da hier von der Natur ein Experiment gemacht worden war, welches schwer oder unmöglich nachzuahmen ist. Es waren nehmlich, wie oben beschrieben, in der ganzen Höbe des Halstheiles die Hinterstränge und ein Theil der Hinterhörner von den vorderen Partien des Rückenmarkes abgetrennt und somit für die inneren Wurzelbündel völlig und für die hinteren Wurzeln zum Theil die Verbindung mit den nach vorn gelegenen Abschnitten der Medulla spinalis aufgehoben.

Im zweiten Falle war ein so unbestimmtes Krankheitsbild vorhanden, dass man viel eher an eine functionelle Neurose, an eine hysterische Neurasthenie denken konnte, als an eine Geschwulstbildung in den Hintersträngen; und gewiss mögen andere Fälle ähnlicher Art, welche für Hysterie genommen werden, auch auf ähnlichen Störungen beruhen. Wenn ein ausgesprochenes typisches Krankheitsbild fehlt, so kann ein derartiger diagnostischer Irrthum wohl vorkommen, besonders wenn nur sensible Störungen schwer controlirbarer Art vorhanden sind und Anomalien der Sehnenreflexe, der Pupillen oder Ataxie sich nicht finden lassen.

Viel instructiver erscheint der vierte Fall. Weder die multiple Sclerose noch die gewöhnlichen Formen von chron. Myelitis des Halstheiles pflegen so vorzugsweise die graue Substanz in erster Linie zu treffen und von dieser aus einerseits degenerative Atrophie der Muskeln und andererseits besonders Analgesie hervorzurufen. Von der multiplen Sclerose weiss man, dass sie gewöhnlich nur mit geringen sensiblen Störungen einhergeht, und auch die chron. Myelitis macht nicht so früh und so ausgedehnte Analgesie. Auch bei der Pachymeningitis hypertroph. cervicalis, bei Compression des Halstheiles durch Tumoren etc. ist die Schmerzleitung nicht so früh und so intensiv gestört, als in Fällen wie der obige, in welchen die graue Substanz der Hinterhörner direct und von innen her destruirt wird. Die Anuahme einer amyotrophischen Lateralsclerose ist wegen des Verhaltens der Sensibilität ausgeschlossen.

Dazu kommt der Mangel von deutlicherer Lähmung in den Unterextremitäten, welcher auf ein Freibleiben der Seitenstränge hinweist, und welche bei allen genannten Krankheitsformen viel früher und regelmässiger eintreten muss. Wächst die Gliawucherung weiter fort, zerstört und comprimirt sie auch die Seitenstränge,

Archiv f. pathol. Anat. Bd. LXXXVII. Hft. 3. 
so werden natürlich Krankheitsbilder wie bei querer Myelitis des Halstheiles entstehen, welche in diesem Stadium eine Unterscheidung mit anderen Krankheitsprozessen schwerlich immer ermöglichen. Ich glaube aber darin nicht febl zu gehen, wenn ich für solche Fälle, bei denen nach den klinischen Symptomen wesentlich nur die vordere und die hintere graue Substanz des Halstheiles destruirt sein kann, also degenerative Muskelatrophie der Oberextremitäten und ausgebreitete Anästhesien ohne wesentliche Lähmung und Rigidität der Unterextremitäten bestehen, die Diagnose auf eine centrale Gliose mit oder obne Zerfall stelle, wie ich sie auch in vorliegendem Falle als wabrscheinlich bei der freilich nur flüchtigen Untersuchung des Kranken hinstellte. - Eigenthümlich war in dem besprochenen Falle noch die complete Analgesie und Anästhesie der Zunge, welche ich auf eine bestimmte Läsion zurückzuführen nicht wage.

In dem letzten Falle von Gliom wurde von Erb eine amyotrophische Lateralselerose diagnosticirt; und in der That wurden auch Vorderhörner und Seitenstränge in weiter Ausdehnung degenerirt und comprimirt gefunden. Dass daneben auch hochgradige Compression und theilweise Degeneration der Hinterhörner und der sensiblen Bahnen bestand, liess sich wegen des normalen Befundes in Bezug auf die Sensibilität nicht diagnosticiren. Es wird durch den Fall die alte Erfahrung bestätigt, dass die Sensibilität bei gleich starkem Drucke viel schwerer leidet als die Motilität; erst wenn wie im Falle IV die graue Substanz der Hinterhörner ganz zerstört ist, scheint sich complete Analgesie einzustellen.

Angesichts der Bemerkungen, welche ich früher (a. a. 0.) über die Differentialdiagnose derartiger centraler Gliombildungen gegenüber den meningealen Tumoren machte, will ich hier nicht noch einmal darauf eingehen, sondern nur noch kurz auf einen anderen Punkt hinweisen. Trotz der hochgradigen Compression und Degeneration in der vorderen grauen Substanz einerseits und der starken Muskeldegeneration andererseits hatten im Falle $V$ doch die peripherischen Nerven bei electrischer Reizung normale Erregbarkeit behalten, offenbar weil noch mindestens eine grössere Anzahl intacter Nervenfasern übrig geblieben war. Wiewohl die vorderen Wurzein im Halstheile stark abgeplattet und verdünnt erscheinen, sah man doch in ihnen noch einen Rest erhaltener Nervenfasern, soweit sich 
jas an Präparaten, die in Müller'scher Flüssigkeit gehärtet sind, beurtheilen lässt. Wenn also auch der Willensreiz, welcher auch die somprimirten Seitenstrangbahnen und die atrophirten und comprinirten Ganglienzellen passiren musste, nicht mehr kräftig genug in die peripherischen Nervenbabnen hineingelangte, um die Muskeln sontrahiren zu können, so vermochte der unterhalb der Druckstelle ingebrachte electrische Strom ganz analog wie bei vielen peripherischen Drucklähmungen dje peripherischen Nerven noch binreichend 3tark zu erregen. Keineswegs erscheint mir aber der Schluss gerechttertigt, dass die peripherischen Bahnen trotz ihres normalen Verhaltens gegen den electrischen Strom nun auch in allen ihren Theilen anatomisch völlig intact seien; das erscheint bei der offenbar vorbandenen Degeneration innerhalb des Rückenmarkes nach dem Waller'schen Gesetze nicht annehmbar. Leider standen mir die peripherischen Nervenstämme für die Untersuchung nicht zur Verfügung. -

Zum Schlusse möchte ich noch hervorheben, dass es sich bei den geschilderten Spaltbildungen wahrscheinlich nicht um so ausserordentliche Raritäten handelt, wie es bisher den Anschein hatte. Man dürfte wohl öfter auf dieselben stossen, wemn man gerade bei $z$ weifelbaften Fällen von Neurosen oder bei weniger ausgeprägten Fällen von angebornen cerebralen Degenerationen genauer ouf den Zustand des Rückenmarkes achtete.

Nachträgllche Bemerkung. In der sehr interessanten Abhandlung ron Koch in Dorpat über die Spina bifida (W. Kocb \#Mittheilungen über Fragen Jer wissenschaftlichen Medicin “, I. Heft), welche mir erst nach dem Abschlusse der obigen Arbeit zuging, ist eine neue Art von Spaltbildung bei einem Falle von angebornem Hydromyelus beschrieben, welche multipel in der grauen Substanz anftritt, ohne dass zugleich in der Höhe der betreffenden Veränderungen der Centralkanal erweitert war. Aus der Beschreibung dieser Spalten, deren Untersuchung an einem Alkoholpräparate gemacht werden musste, lässt sich vorläufig noch nicht ersehen, welche Beziehungen dieselbe mit den unsrigen haben. Sie werden als einfache Lücken ohne Zellenbelag und ohne Beziehungen zo den Blutgefässen und Lymphräumen beschrieben und ihre Bedeutung vom Autor selbst unbestimmt gelassen. Sehr merkwürdig ist ferner die Beobachtung von $\mathrm{K} \mathrm{och}$ in dem gleichen Falle, dass die weisse Substanz in den Präparaten desselben Falles „in der Gestalt von Bändeln zusammengeschoben " erschien. $O b$ damit etwas Analoges wie in meinem Falle III gegeben ist, wo Bündel feiner Nervenfasern nebst regelmässig dazugehörigen Gefässen in den Hintersträngen sich fanden, bleibt abzuwarten. 


\section{Erklärung der Abbildungen.}

Tafel X.

Die Rückenmarksquerschnitte sind in doppelter linearer Vergrösserung gezeichnet.

Fig. 1. (Fall I.) Spaltbildung im linken Hinterhorn; circumscripte Degeneration der Seitenstränge in der Nähe der Spitze der Hinterhörner; die Hinterhörner verlaufen gestreckter.

Fig. 2. (Fall I.) Ependymwncherung in der Gegend des Centralkanales; Gliawucherung in den Hinterbörnern; Degeneration der Seitenstränge wie in Fig. 1.

Fig. 3. (Fall I.) Spaltbildung in der Medulla oblongata. Pyramiden etwas abgeflacht.

Fig. 4. (Fall III.) Dorsalthell. Erweiterter Centralkanal, zum Theil vor dem einen Vorderhorn gelegen. Die schattirte Partie vor der Spalte stellt das gewucherte Gliagewebe dar. Das eine Hinterhorn viel kräftiger entwickelt als das andere.

Fig. 5. (Fall III.) Oberster Dorsaltheil. Erweiterter Centralkanal mit Spalt in einem Hinterhorn.

Fig. 6. (Fall IV.) Lumbaltheil. Höhle in einem der Hinterhörner. Rarefication der Substanz des andersseitigen Vorderhorns.

Fig. 7. (Fall 1V.) Dorsaltheil. Spalt im linken Hinterhorn.

Fig. 8. (Fall IV.) Halsanschwellung. Zerstörung fast der ganzen grauen Substanz durch Höhlenbildung. (Die Schattirung der Umgebung der Höhle, welche zum grössten Theile die vorbandene Gliawucherung verdentlichen soll, nach vorn zu etwas zu breit gezeichnet.) Elgenthümliche Difformität des Rïickenmarkes. 